\title{
CONSTRUÇÕES BINOMINAIS DO TIPO SN1 DE SN2
}

\author{
Carolina Piechotta Martins SANTOS ${ }^{1}$ \\ Karen Sampaio Braga ALONSO ${ }^{2}$
}

\begin{abstract}
Resumo: Este artigo tem por objetivo investigar a flutuação de sentido quantidadequalidade licenciada pelo uso de construtos binominais do tipo SN1 de SN2, como xícara de chá, no Português do Brasil. A pesquisa é baseada na perspectiva teórica da Linguística Funcional Centrada no Uso (BYBEE, 2010; BARLOW; KEMMER, 2000; TOMASELLO, 2003, TRAUGOTT, 2008) e busca descrever as propriedades morfossintáticas, semântico-pragmáticas e cognitivas dos usos das construções que favorecem uma leitura ora qualitativa ora quantitativa, no que se refere à relação entre SN1 e SN2.
\end{abstract}

Palavras-chave: Linguística Funcional Centrada no Uso. Construções Binominais. Quantidade. Qualidade.

\section{Introdução}

O presente estudo tem por objetivo geral investigar um conjunto de construtos que podem ser mapeados em construções binominais ora quantitativas ora qualitativas do tipo SN1 de SN2 no Português do Brasil ${ }^{3}$. Para tanto, faremos uso dos fundamentos teórico-metodológicos da Linguística Funcional Centrada no Uso e, portanto, congregaremos argumentos de ordem cognitiva, formal e semântico-discursiva. Brevemente, para ilustrar a proposta do artigo, consideremos, de início, três exemplos:

\footnotetext{
${ }^{1}$ UFRJ - Universidade Federal do Rio de Janeiro - Programa de Pós-graduação em Linguística. Rio de Janeiro - Rio de Janeiro - Brasil. 21941-917 - carolpms@hotmail.com

${ }^{2}$ UFRJ - Universidade Federal do Rio de Janeiro - Departamento de Linguística e Filologia. Rio de Janeiro - Rio de Janeiro - Brasil. 21941-917 - karensampaio@letras.ufrj.br

${ }^{3}$ Dentro do Português do Brasil, delimitamos o gênero "crônica" para a realização de uma análise qualitativa do grupo de usos que é escopo da presente pesquisa. Complementarmente à análise qualitativa, em que foram estabelecidas as primeiras hipóteses da dissertação, foi feita uma análise quantitativa de dados, a qual se baseou no Corpus do Português.
}

http://dx.doi.org/10.21165/gel.v14i1.1452 
(1) litro de leite

(2) roupa de veludo

(3) xícara de chá

No exemplo (1), litro de leite, há uma relação de caráter quantitativo entre SN1 e SN2, já que N1 (litro) refere-se a uma quantidade determinada de N2 (leite), isto é, há uma relação parte-todo entre os dois nomes, em que, mais especificamente, SN1 delimita o conteúdo referido por SN2. Em (2), roupa de veludo, há uma relação de caráter qualitativo entre SN1 e SN2, em que de veludo representa o material de que a roupa é feita.

Já no exemplo (3) - xícara de chá -, podem-se depreender quaisquer dos dois sentidos relatados anteriormente no comentário aos construtos (1) e (2), a saber: qualitativo e quantitativo. Mais especificamente, o exemplo (3) pode referir-se a um tipo de xícara, ou seja, uma xícara específica para tomar chá (valor qualitativo) ou, ainda, à quantidade de chá, isto é, a partir de uma relação parte-todo entre xícara e chá, em que xícara delimita certa quantidade de chá, que representa o todo (valor quantitativo).

Portanto, assumimos como objeto deste estudo um conjunto de construtos com comportamento similar ao de xícara de chá, que podem ser mapeados em construções qualitativas e quantitativas, a depender do contexto. Defendemos, dentro da abordagem teórica adotada, que essa dupla possibilidade de interpretação das construções binominais associa-se diretamente ao esquema imagético CONTÊINER (LAKOFF, 1987; LAKOFF; JOHNSON, 1987) e, mais especificamente, ao esquema DENTROFORA, como será retratado ao longo do artigo.

Ao lado de fatores de ordem cognitiva, os construtos binominais serão também descritos em termos de suas marcas formais, como, por exemplo, a presença ou não de especificador antes de N1 (um copo de leite X Ø copo de leite). Tal descrição dos aspectos formais tem como finalidade verificar as pistas linguísticas para que as instâncias sejam interpretadas como construções qualitativas ou como construções quantitativas. Além disso, também observaremos fatores como presença/ausência de modificador após N2 e o tipo semântico do verbo e do adjetivo. Assim, o que pretendemos demonstrar é que uma série de fatores de diferentes naturezas contribui para se chegar à resposta tomada como objetivo geral do artigo: o que leva uma 
combinação lexical dentro de uma estrutura binominal a ser entendida com valor quantitativo ou com valor qualitativo?

Para realização da presente pesquisa, conforme já mencionado antes, tomamos como base o arcabouço teórico da Linguística Funcional Centrada no Uso (BYBEE, 2010; BARLOW; KEMMER, 2000; TOMASELLO, 2003; TRAUGOTT, 2008; TRAUGOTT; TROUSDALE, 2013), de cujos pressupostos teórico-metodológicos podemos destacar as seguintes premissas: (i) rejeitam a autonomia da sintaxe; (ii) incorporam a semântica e a pragmática à análise; (iii) consideram que a gramática, por ser vista como representação cognitiva da experiência dos indivíduos com a língua, pode ser afetada pelo uso linguístico; (iv) não fazem distinção estrita entre léxico e gramática; (v) entendem que os dados para análise linguística são enunciados que ocorrem no discurso natural; (vi) assumem que a linguagem faz parte da cognição.

Ainda dentro dessa perspectiva teórica, a estrutura linguística é entendida como fruto de processos cognitivos mais gerais, bem como de frequência de uso. A gramática de uma língua seria, assim, resultante de associações cognitivas e de cristalizações de uso de determinadas sequências, as quais passam a ser encaradas como unidades teóricas complexas ou pareamentos de forma e sentido, chamados de construção gramatical (GOLDBERG, 1995; CROFT, 2001).

Sendo assim, a pesquisa assume também como referencial teórico os estudos em gramática das construções (GOLDBERG, 1995; CROFT, 2001) por entender que a gramática de uma língua não consiste de um conjunto de regras de manipulação sintática, mas é caracterizada por uma série de construções entrelaçadas no formato de uma rede, na qual construções mais básicas gerariam construções mais complexas. Entendemos por construção gramatical a unidade que associa forma e função e que se constitui como parte do nosso conhecimento sobre a língua.

Dessa forma, trabalhamos com os conceitos $^{4}$ de macroconstrução, mesoconstrução e microconstrução, conforme propostos por Traugott (2008). Assumindo o postulado da autora de uma possível hierarquização de construções,

\footnotetext{
${ }^{4}$ Para o presente artigo, ressalta-se que estaremos fazendo uso da nomenclatura de Traugott (2008). A autora estabelece níveis de análise das construções:

i) macroconstruções - cobrem o nível esquemático máximo (SN1 de SN2);

ii) mesoconstruções - correspondem ao conjunto de construções que apresentam comportamento semelhante (construções qualitativas, quantitativas, etc.);

iii) microconstruções - tipos de construções individuais (xícara de chá, taça de vinho, etc.) e

iv) construtos - tokens empiricamente comprovados, são o lugar da mudança.
} 
entendemos que, a partir da macroconstrução binominal SN1 de SN2, alguns construtos, como xícara de chá (já apresentado anteriormente), podem ser ora mapeados pela mesoconstrução qualitativa, ora pela mesoconstrução quantitativa, a depender do contexto comunicativo em que são usados. Enquanto isso, outros construtos como litros de leite e roupa de veludo (também já referidos no início do texto) apresentam apenas uma das leituras, a saber: quantidade e qualidade, respectivamente.

Conforme o exposto, partimos, então, do princípio de que o sentido das formas linguísticas não pode ser analisado fora do contexto, já que este é responsável por orientar a leitura ora quantitativa ora qualitativa, a depender da mesoconstrução à qual o construto está associado. A hipótese geral é, portanto, a de que esses construtos binominais podem ser tratados em termos de mapeamentos em diferentes construções gramaticais e que a orientação desse mapeamento está diretamente ligada a fatores favorecedores de diferentes naturezas, a saber: cognitivas; semântico-pragmáticas; morfossintáticas, etc. O objetivo geral deste trabalho, como já dito, é, então, o de descrever algumas dessas propriedades cognitivas, semântico-pragmáticas e morfossintáticas de um conjunto de construtos com estrutura binominal que podem ser mapeados em construções de cunho qualitativo e quantitativo. Relacionados a esse objetivo, seguem-se alguns objetivos mais específicos que norteiam a tese do artigo:

(a) Em termos da dimensão cognitiva associada ao conjunto de construtos que são o foco do trabalho, identificar o esquema imagético que dá conta da "alternância" quantidade e qualidade;

(b) Identificar as propriedades cognitivas específicas da quantidade e aquelas associadas à qualidade e como essas propriedades contribuem para a orientação da interpretação qualitativa ou quantitativa desses usos;

(c) Identificar e avaliar como fatores de natureza semântico-pragmática (tipo semântico do verbo e dos modificadores que são observados quando ampliamos o contexto morfossintático analisado) atuam no mapeamento desse grupo de construtos tomado como objeto da pesquisa nas mesoconstruções qualitativa e quantitativa; 
(d) Identificar e verificar como fatores de cunho mais formal, como presença/ausência e natureza de especificadores e presença/ausência de modificadores, funcionam como pistas para a interpretação qualitativa ou quantitativa; e

(e) Ainda no plano da forma, descrever a alternância de núcleo sintático na leitura qualitativa em relação à quantitativa.

Esses objetivos tomam corpo a partir de algumas hipóteses a respeito do comportamento dos construtos estudados, a saber:

(a) Dada a natureza dos elementos que ocupam o slot (posição aberta na construção) de SN1 (por ex.: xícara, garrafa, copo, etc.) em relação à natureza dos elementos que ocupam SN2 (champanhe, vinho, coalhada, etc.), postula-se que a possibilidade de essas combinações morfossintáticas serem mapeadas ora como construções qualitativas, ora como construções quantitativas está relacionada de forma mais geral ao esquema imagético CONTÊINER.

(b) Baseando-se em estudos anteriores (ALONSO, 2010; ALONSO; FUMAUX (2010, inédito), etc.), postula-se que: i) a interpretação quantitativa está relacionada mais diretamente à propriedade da plexidade; ii) a interpretação qualitativa se associa mais especificamente à ideia de finalidade (serventia);

(c e d) Incorporando os conceitos-base da epistemologia adotada, entende-se que as marcas linguísticas recorrentes na leitura qualitativa e aquelas que aparecem frequentemente quando a leitura é quantitativa funcionam como pistas que orientam o mapeamento forma-sentido das mesoconstruções estudadas.

(e) Tendo por base estudos anteriores (CROFT, 2001; MATEUS et al., 2003, etc.), defende-se que o núcleo da construção qualitativa seja N1 - [um [copo] de vinho] - e que o núcleo da construção quantitativa seja N2 - [um copo de [vinho]]; logo, postulase que a alternância de núcleo deve acompanhar a alternância interpretativa desse grupo de construtos adotado como escopo da pesquisa. 
Em termos metodológicos, para cumprir o desenvolvimento dos objetivos estabelecidos no presente artigo, foi feita, inicialmente, uma análise qualitativa dos dados, para a qual foi tomado como corpus o livro de crônicas Em algum lugar do paraíso, de Luis Fernando Veríssimo (2011). Nessa análise, foram catalogados (e analisados) os construtos binominais que apresentam flutuação de sentido entre qualidade e quantidade - o caso de copo de refrigerante, garrafa de água, taça de vinho, etc. A partir dessa coleta de dados, recortamos ${ }^{5}$ seis padrões de construtos binominais, em que SN1 é preenchido lexicalmente e SN2 é um slot aberto, a saber: copo de SN2, garrafa de SN2, taça de SN2, lata de SN2, pote de SN2 e vidrinho de SN2. Nessa primeira etapa da análise de dados, bem como a partir dos relatos da literatura que embasa o artigo, foram postuladas as hipóteses gerais da pesquisa, já apresentadas.

Para verificar os fatores que permitem que os construtos sejam mapeados ora pela mesoconstrução qualitativa, ora pela mesoconstrução quantitativa, partiu-se para uma análise de dados de cunho quantitativo, fazendo-se uso da ferramenta de busca disponível no site Corpus do Português ${ }^{6}$. A busca foi feita localizando, no corpus online, dados dos seis padrões de construtos do livro de crônicas mencionado - ou seja, foram buscados exemplos que mantinham os preenchimentos lexicais de N1 já citados.

Em seguida, observamos e definimos os fatores que seriam controlados na análise quantitativa. Depois da coleta dos dados, utilizamos o programa Access para a criação do banco de dados e, em seguida, o programa SPSS (Statistical Package for the Social Sciences). Com esse programa, foi possível obter a frequência de ocorrência de cada um dos tipos encontrados, além de realizar o cruzamento dos fatores estabelecidos como parâmetros de análise.

\footnotetext{
${ }^{5}$ Para o recorte desses padrões binominais, tomou-se o seguinte procedimento: partimos dos resultados da análise qualitativa e fizemos uma busca online no Corpus do Português pelos construtos relacionados às microconstruções xícara de SN2, garrafa de SN2, potes de SN2, etc., que já tinham um construto aparecendo na análise dos dados do livro de crônicas analisado.

$6<$ www.corpusdoportugues.org $>$. Nossa escolha do corpus foi orientada pelo método de busca, já que no Corpus do Português nos foi permitido procurar pelos padrões taça de, copo de, etc.
} 


\section{Pressupostos teóricos}

Adotamos, nesta pesquisa, uma visão dinâmica da gramática, que prevê a atuação de mecanismos expressivos à subjetividade dos falantes, que, por sua vez, recriam padrões gramaticais. Com a repetição desses padrões, ocorre a ritualização de usos de determinadas estruturas de onde emerge a gramática de uma língua. A gramática é composta de construções, ou seja, de padrões convencionados de forma e sentido (GOLDBERG, 1995); assim, cabe ao linguista descrever esses padrões e as relações existentes entre eles. Essa proposta se aproxima dos objetivos deste trabalho, uma vez que se busca compreender padrões binominais de uso em termos de pareamentos formasentido que flutuam entre o domínio da qualidade e o da quantidade.

Ainda sobre a construção da gramática, é fundamental recorrermos à proposta de Tomasello (2003), que une o aprendizado e uso da língua com habilidades sociais e cognitivas. A gramática, então, está essencialmente relacionada a mecanismos gerais da cognição, já que, ao produzirmos e compreendermos enunciados, atualizamos vários desses mecanismos, como transferência entre domínios, armazenamento de informação na memória, processamento e interpretação da informação, etc.

Para o autor, a linguagem é uma forma de cognição para fins de comunicação interpessoal. Nessa abordagem, “aprender a usar símbolos linguísticos significa aprender a manipular o interesse e a atenção de outro agente intencional com quem se está interagindo” (TOMASELLO, 2003, p. 183). Em termos da estruturação linguística, a mudança de foco pode ser descrita em termos de mudança de núcleo sintático. Isso pode ser percebido nas leituras qualitativa - em que se tem [[xícara] de chá] para tratar da xícara que se usa para servir o chá, cujo foco recai sobre a xícara (N1) - e quantitativa, em que se tem [xícara de [chá]], em que o foco recai sobre o chá (N2).

A Linguística Funcional Centrada no Uso, adotada como referencial teórico, se apresenta como resultante da combinação da tradição funcionalista com a abordagem da Linguística Cognitiva, de cuja tradição foram mais especificamente tomados alguns conceitos básicos que serão retomados na análise de dados.

A Linguística Cognitiva - adotada primeiramente por um grupo restrito de estudiosos, dentre os quais se destacam George Lakoff, Ronald Langacker, Leonard Talmy, Charles Fillmore e Gilles Fauconnier (FERRARI, 2011) - concebe uma visão na 
qual a linguagem relaciona-se com outras capacidades cognitivas, sendo parte da cognição. Além disso, postula-se que nossa visão de mundo é limitada pelo corpo e a apreensão da realidade é circunscrita a aspectos da cognição humana, isto é, a relação entre a palavra e o mundo não é direta, mas mediada pela cognição.

Bybee (2010) traz uma noção crucial para o trabalho. Segundo a autora, as informações mais frequentes são acessadas mais facilmente; logo, há uma maior possibilidade deste uso servir de base para categorização de novos itens. Dessa forma, postulamos que a construção binominal SN1 de SN2 pode ser acessada pelo falante para categorizar outras noções, a partir da noção de qualidade atrelada a essa construção. Propomos que construtos como xícara de chá perderam seu valor original de indicação de tipo de xícara, para passar a significar uma quantidade que cabe em uma xícara. O construto xícara de chá, por exemplo, afasta-se de um construto prototipicamente qualitativo, como casa de madeira, ao mesmo tempo em que também não se enquadra na categoria de típico quantitativo, como litros de leite. Sendo assim, nos interessa, nesta pesquisa, exatamente esses construtos que estão na fronteira entre a qualidade e quantidade. Para Bybee (2010), os exemplares que entram em uma categoria podem se distanciar dos exemplares fortes, dependendo do grau de similaridade entre eles.

Outro postulado defendido pela Linguística Cognitiva é a não isolabilidade entre conhecimento enciclopédico e conhecimento de dicionário, bem como o predomínio daquele sobre esse. O conhecimento de dicionário refere-se ao significado das palavras e restringe-se ao domínio da aplicação da semântica lexical; e o enciclopédico refere-se ao conhecimento de mundo ou não linguístico, isto é, as relações entre sentido e contexto (domínio da pragmática).

Mais especificamente, como a Linguística Cognitiva adota uma perspectiva baseada no uso, tem como uma de suas principais hipóteses a noção de que o contexto orienta a construção do significado. Assim, rejeita-se a ideia de um dicionário mental que contenha o conhecimento semântico de forma separada de outros tipos de conhecimento. Portanto, a divisão do significado linguístico em semântica e pragmática é considerada problemática. Defende-se, então, a ideia de que as palavras sejam interpretadas em relação a frames $^{7}$ ou domínios de experiência. A consideração do

\footnotetext{
${ }^{7}$ É o sistema estruturado de conhecimento em relação ao qual uma palavra deverá ser interpretada. Por exemplo, para interpretar os verbos comprar, vender, pagar ou custar devemos acessar o frame de EVENTO COMERCIAL.
} 
contexto será tratada ao longo de toda a análise do trabalho, e a referência ao conceito de frame semântico será importante para compreendermos alguns usos desses grupos de construtos e a escolha pela interpretação quantitativa, que se mostrou menos frequente, como se poderá ver na análise dos dados.

Dentro dessa abordagem, a Gramática das Construções também é tomada como referencial teórico fundamental para a pesquisa, já que admite o pareamento formasignificado como essencial na estruturação da gramática de uma língua. Portanto, cabe tratarmos do conceito de construção, proposto por Goldberg (1995), a partir do seguinte trecho:

C é uma construção se e somente se $\mathrm{C}$ é um par forma-significado $<\mathrm{Fi}$, $\mathrm{Si}>$, de tal forma que nenhum aspecto de Fi ou de Si seja estritamente previsível a partir de partes componentes de $\mathrm{C}$ ou a partir de outras construções previamente estabelecidas. (GOLDBERG, 1995, p. 4, tradução nossa) $)^{8}$

Assim, podemos perceber que construções são unidades básicas da linguagem, entendidas como qualquer elemento formal diretamente associado a algum sentido. A noção de construção abrange uma variedade de unidades linguísticas e, por isso, distribui-se em um continuum. Elas podem, portanto, ser instanciadas por meio de elementos de diferentes complexidades estruturais, a saber: morfemas simples, palavras, expressões idiomáticas, sintagmas fixos com significado composicional e até mesmo padrões sintáticos mais abstratos. Desse modo, poderíamos ter construções partindo de elementos específicos, como: o item lexical casa, a expressão idiomática Maria vai com as outras, até padrões mais abstratos como a construção transitiva.

A semântica cognitiva inclui na sua descrição estruturas capazes de capturar a organização do nosso conhecimento: de um lado os esquemas imagéticos; do outro, frames e Modelos Cognitivos Idealizados $\left(\mathrm{MCI}^{9}\right)$, desenvolvidos por Fillmore e Lakoff, respectivamente. Além dessas estruturas de conhecimento, o significado das unidades linguísticas também é descrito a partir de mecanismos cognitivos, como os ajustes focais, metáfora, metonímia e mesclagem conceptual (ALMEIDA et al., 2009).

\footnotetext{
${ }^{8}$ Trecho original: "C is a CONSTRUCTION iff def $\mathrm{C}$ is a form-meaning pair $<\mathrm{Fi}$, Si $>$ such that some aspect of Fi or some aspect of Si is not strictly predictable from C's component parts or from other previously established constructions.” (GOLDBERG, 1995, p. 4)

${ }^{9}$ Modelos Cognitivos Idealizados (MCI) são representações cognitivas estereotipadas que agrupam frames distintos. Interpretarmos a palavra solteiro, por exemplo, a partir do MCI de CASAMENTO (FERRARI, 2011).
} 
Dentre as estruturas citadas, uma tem importância central neste estudo: os esquemas imagéticos, estruturas que refletem padrões recorrentes que experienciamos em nossa interação sensório-motora com o mundo. Esses esquemas, como já mencionado, emergem a partir da nossa experiência corporificada e ganham importância no nível conceptual justamente por derivar dessa experiência. Alguns conceitos associados a esses esquemas são: dentro/fora, percurso, perto/longe, contêiner, entre outros. O esquema imagético PERCURSO, por exemplo, pode ser visto na metáfora conceptual AMOR É UMA VIAGEM (LAKOFF; JOHNSON, 1980), que pode ser exemplificada nas frases seguintes: Veja a que ponto chegamos; Não podemos voltar atrás agora. Nessas frases, a metáfora principal é a viagem e há vários tipos de viagem que podem ser feitas: de carro, de trem, de navio, isto é, não há uma única imagem consistente em que todas as metáforas de viagem se encaixem.

Outro domínio do esquema imagético está relacionado ao CONTÊINER, muito frequente e, portanto, linguisticamente realizado de muitas maneiras. Esse esquema imagético considera o elemento interior, o limite do espaço e o elemento exterior, além de ser muito complexo, constituída por uma rede de metáforas conceptuais. Observemos:

(4) Não consigo tirar essa música da cabeça. (MENTE É UM RECIPIENTE)

(5) Quem te deu essa ideia? (IDEIAS SÃO OBJETOS)

(6) Não consegui pegar o sentido desse texto. (COMPREENDER É PEGAR)

O esquema imagético DENTRO-FORA que reflete o domínio do CONTÊINER é resultado de nossas experiências com objetos desse tipo, ocasionando expressões, como vemos em:

(7) O homem caminhou para dentro do sítio.

(8) A criança jogou o brinquedo fora.

Ou ainda, alguns usos metafóricos, como em:

(9) Você precisa colocar a raiva para fora. 
(10) Ela se enfiou em uma calça confortável.

No exemplo (9), vemos o corpo humano como um contêiner de onde sai a raiva e, em (10), a calça é retratada como um contêiner para dentro do qual a pessoa se move.

Observemos, em seguida, um exemplo do nosso corpus em que o esquema imagético CONTÊINER orienta a leitura da instância vidrinhos de remédio.

(11) Ficou famoso o caso do navegador português que mandava telegramas dentro de vidrinhos de remédios, para chegar mais rápido. E do outro, brasileiro, que escreveu um bilhete pedindo socorro, rasgou o bilhete em vários pedacinhos, colocou cada pedacinho dentro de uma garrafa e mandou cada garrafa numa direção para aumentar suas chances de ser salvo. (VERISSIMO, 2011, p. 133)

No exemplo acima, o interlocutor está descrevendo histórias em uma ilha deserta e mostra como as pessoas faziam para serem localizadas. O uso da expressão dentro de orienta para a leitura qualitativa, pois acessa o esquema imagético DENTRO-FORA, que reflete o domínio do CONTÊINER. Assim, os vidrinhos de remédios são vistos como contêineres dentro dos quais os telegramas eram enviados.

Ainda dentro da perspectiva da Linguística Cognitiva, outra noção importante para esta pesquisa é a de contabilidade dos nomes trazida por Talmy (2006). O autor propõe um sistema envolvendo quatro categorias gramaticais relacionadas ao conceito de quantidade, a saber: dimensão, plexidade, delimitação e divisão. Dentre essas noções, a ideia de plexidade mostrou-se fundamental na análise de nossos dados.

A plexidade está relacionada à quantidade de elementos equivalentes, relativos à matéria/objeto ou ação/evento. Quando a categoria envolvida é matéria, a plexidade equivale à noção de número, com suas noções de singular e plural. Quando a categoria envolvida é ação, não há correspondência com as noções tradicionais.

Duas operações cognitivas podem ser atribuídas a nomes e verbos: uniplexidade e multiplexidade. No primeiro caso, a entidade é conceptualizada como unitária (A flor se abriu), já no segundo ocorre a cópia do referente originalmente individuado para vários outros pontos do espaço (As flores se abriram). Um item multiplexo, como 
plateia, pode ser convertido em uniplexo por meio de outra operação cognitiva chamada de extração de unidade, que requer a inserção de elementos gramaticais como "um $\mathrm{N}$ de” (ex: Um membro da plateia).

Essa operação cognitiva de extração de unidade pode ser vista em nossos dados, como exemplificado abaixo:

(12) “- Posso lhe oferecer uma panhe de chamtaça? Quer dizer, uma taça de champanhe?” (VERISSIMO, 2011, p. 70)

Nesse exemplo, a extração de unidade é feita através da expressão uma taça de. Desta forma, a taça refere-se à parte de champanhe, que representa o todo. Cabe ressaltar que, no exemplo acima, o frame ativado pelo verbo oferecer e o MCI de recepção em casa, que envolve receber convidado para jantar/almoçar, fornecem a base motivadora para a interpretação da cena descrita.

Percebemos, então, que a noção de esquema imagético relaciona-se a diferentes usos linguísticos que refletem a experiência corpórea dos seres humanos no espaço físico.

Analisaremos também, em relação às duas leituras, qualitativa e quantitativa, os fatores formais que podem estar relacionados com cada um dos padrões construcionais. Para explicarmos o uso das construções binominais, controlamos os seguintes fatores:

(I) Frequência de cada padrão binominal;

(II) Tipo semântico do verbo;

(III) Elemento à esquerda de N1;

(IV) Modificador à esquerda de N2.

Foram feitos também alguns cruzamentos, relacionando os fatores (II), (III) e (IV) com a leitura qualitativa ou quantitativa, a fim de observamos as propriedades formais que servem de pistas para a interpretação qualitativa e quantitativa. Ressaltamos aqui que o sentido da construção não é dado, mas é construído a partir do contexto, no curso de uma interação. 
Passemos agora à análise de alguns dados do corpus, observando as propriedades dos construtos que estamos estudando aqui:

(13) "Decidiram suspender a partilha dos discos antes de se atracarem e rolarem, rosnando e trocando insultos, pelo carpete. Ele foi até a janela, respirar fundo. Ela foi examinar os fundos do armário para ter certeza de que não estavam esquecendo de nada. Foi quando ela deu com a garrafa de champanhe.” (VERISSIMO, 2011, p. 46)

Ao longo da leitura do trecho, o narrador nos fornece pistas linguísticas (como a descrição das ações dos personagens, o uso do advérbio de tempo quando) que valorizam o continente e não o conteúdo. Percebemos que o foco recai sobre o continente, já que a garrafa passa a ser um referente no espaço e se encontra nos fundos do armário. Além disso, a construção encontra-se determinada pelo artigo definido $a$. Dessa forma, a construção binominal destacada recebe leitura qualitativa, tendo garrafa como núcleo, podendo ser transcrita como em: [uma [garrafa] de champanhe].

Vejamos mais alguns exemplos de construções binominais que recebem leitura qualitativa, retirados de Verissimo (2011).

(14) "Existem várias histórias de garrafas lançadas ao mar com um bilhete dentro. Eu mesmo certa vez coloquei um bilhete dentro de uma garrafa e larguei no mar. [...] Ficou famoso o caso do navegador português que mandava telegramas dentro de vidrinhos de remédios, para chegar mais rápido.” (VERISSIMO, 2011, p. 133)

(15) "E do outro, brasileiro, que escreveu um bilhete pedindo socorro, rasgou o bilhete em vários pedacinhos, colocou cada pedacinho dentro de uma garrafa e mandou cada garrafa numa direção para aumentar suas chances de ser salvo. E do outro que usou uma garrafa de vinho para mandar um bilhete e uma meia garrafa para mandar um P.S. E o náufrago prolixo que só mandava garrafão?” (VERISSIMO, 2011, p. 133)

(16) "Você pode imaginar variações para esta história. Garrafas de champanhe começam a dar na praia, em sucessão. Cada uma com um bilhete dentro.” (VERISSIMO, 2011, p. 133) 
Nos três exemplos acima, o interlocutor está descrevendo histórias em uma ilha deserta e mostra como as pessoas faziam para serem localizadas. Em (14), o uso da expressão dentro de orienta para a leitura qualitativa, pois acessa o esquema imagético DENTRO-FORA, que reflete o domínio do CONTÊINER. Assim, os vidrinhos de remédios são vistos como contêineres dentro dos quais os telegramas eram enviados. Em (15), alguns fatores apontam para a leitura qualitativa, a saber: a presença do verbo usar antes da construção; utilização da garrafa como meio para enviar um bilhete; relação do tamanho da garrafa com o tamanho da mensagem; e a afirmação de que as garrafas começaram a aparecer na praia. Além disso, nesse exemplo, ocorre a presença do artigo indefinido uma antes da construção.

Em (14), (15) e (16) o foco está no vidrinho e na garrafa, respectivamente, e temos as seguintes construções:

[[vidrinhos] de remédios],

[uma [garrafa] de vinho] e

[uma [garrafa] de champanhe].

\section{Procedimentos de análise}

Passamos, agora, a explicitar as etapas de que lançamos mão para a análise dos construtos em foco. Nesta pesquisa, cujo principal objetivo é analisar a flutuação de sentido quantidade-qualidade em construtos do tipo SNI de SN2, tomamos como primeiro passo a coleta das construções em foco em um livro do gênero “crônicas”, intitulado Em algum lugar do Paraíso, de Luis Fernando Verissimo (2011). O livro é composto por 41 crônicas em que o autor aborda situações cotidianas e questionamentos atemporais que permeiam a experiência humana, como o amor, o tempo e a morte. As narrativas são contadas em um tom informal e com certa dose de humor, como podemos ver no trecho abaixo, em que Verissimo traz uma reflexão sobre a questão do tempo, resgatando Adão e Eva:

[...] mas feliz era Adão, o primeiro homem. Não porque estava no jardim do Paraíso, com tudo em volta para saciar sua fome e sua sede, mas porque não sabia do tempo e da morte.

Vivia num eterno presente, num eterno domingo. O que vinha depois 
da passagem da sombra da noite não era o dia seguinte, era o mesmo dia, ou até o dia anterior, quem se importava? Adão, sozinho no Paraíso, era um homem feliz porque era um homem sem datas.

Mas quando Deus colocou Eva ao lado de Adão, a primeira coisa que ela perguntou, ainda úmida da criação, só para puxar assunto, foi: “Que dia é hoje?”, e ele sentiu que sua paz terminara. (VERISSIMO, 2011, p. 7)

O fenômeno estudado é amplamente encontrado nos mais diferentes gêneros textuais; no entanto, concentramos nossa análise no gênero “crônica”, pelo fato de, entre outros fatores, ele apresentar como conteúdo temático fatos do cotidiano. Muitos exemplos de construtos em análise, como garrafa de vinho e taça de champanhe, apresentam nomes que fazem referência a objetos do dia a dia, como garrafa, taça. Além disso, trata-se de um gênero híbrido - a crônica apresenta em sua composição sequência textual variada -, o que parece favorecer o aparecimento das construções em foco. Apesar de haver certa tendência à narração no corpus escolhido, a composição do gênero em foco conta com sequências textuais variadas. Vejamos um exemplo:

(17) “- Quer dizer que eu vou conhecer o seu famoso suflê de queijo?

- Espero que ele não decepcione. Sabe como é suflê.

- Me disseram que o seu nunca falha.

- Bom, até hoje ninguém se queixou.

Duplo sentido, mas com classe. O script continua funcionando

- Posso lhe oferecer uma panhe de chamtaça? Quer dizer, uma taça de champanhe?”

[...]

- Obrigado.” (VERISSIMO, 2011, p. 70)

Essa sequência textual apresenta como conteúdo temático o suflê de queijo. Além disso, caracteriza-se como dialogal, visto que há uma interação verbal entre dois interlocutores e são apresentados segmentos estruturados em turnos de fala. Essa fase da interação pode ser considerada transacional ${ }^{10}$, ou seja, uma fase de troca de turnos entre as duas sequências fáticas: a de abertura (Quer dizer que eu vou conhecer o seu famoso suflê de queijo?) e a de encerramento (Obrigado.).

\footnotetext{
${ }^{10}$ Adam (1992) divide a sequência dialogal em duas: as fáticas e as transacionais. As fáticas têm a função de abrir e fechar a interação; e as transacionais compõem o corpo da interação.
} 
Nesse sentido, o corpus escolhido para uma análise qualitativa prévia dos dados reflete nosso interesse em trabalhar com o uso, com dados reais ${ }^{11}$, já que não postulamos a existência de uma gramática pronta, acabada; ao contrário, acreditamos que os eventos de uso são fundamentais para a continuidade da estruturação do sistema, já que representam tanto o output do sistema do falante, como fornecem o input para os sistemas de outros falantes. Esse mecanismo, que tem como base o uso, ocasiona reanálises, analogia e outros processos que geram alterações e extensões no emprego de expressões linguísticas. Os novos usos que ocorrem como consequência desse processo podem ter um aumento na sua frequência e serem incorporados ao sistema.

Em seguida, a fim de ver o que é mais caracterizador (aspectos mais recorrentes) desse grupo de construtos, bem como os fatores que permitem que os construtos sejam mapeados ora pela mesoconstrução qualitativa, ora pela mesoconstrução quantitativa, partimos para uma análise quantitativa de dados. Para tanto, partiu-se da análise qualitativa, quando se obteve, dos construtos encontrados, seis microconstruções, ou seja, seis padrões de combinações binominais com distintos itens lexicais preenchendo SN1 e mantendo com SN2 uma relação potencialmente ambígua, ou seja, uma relação em que, a depender do contexto, pode ser interpretada como qualitativa ou quantitativa. Essa primeira fase da análise de dados foi muito importante, tendo em vista que, a partir dela, da literatura sobre o assunto e dos pressupostos básicos da perspectiva teórica adotada, foi possível traçar as hipóteses deste trabalho.

Entretanto, conforme se viu na descrição das hipóteses e dos objetivos apresentados anteriormente, era preciso olhar uma quantidade maior de dados para verificar/confirmar os fatores responsáveis pela leitura qualitativa ou quantitativa dos construtos binominais. Para tanto, como mencionado, partimos dos resultados da análise qualitativa e fizemos uma busca online no Corpus do Português pelos construtos relacionados às microconstruções xícara de SN2, garrafa de SN2, potes de SN2, etc., que já tinham um construto aparecendo na análise dos dados do livro de crônicas mencionado. Assim, em vez de chegar a diferentes conclusões somente a partir dos exemplos do livro de crônicas, pudemos identificar os fatores relevantes para a leitura qualitativa e para a leitura quantitativa por meio de um número maior de construtos para cada microconstrução selecionada. Por exemplo, no livro, aparece um exemplo de

\footnotetext{
${ }^{11}$ Apesar de não estarmos trabalhando com o uso espontâneo, isto é, com a fala, o gênero escolhido para análise apresenta marcas típicas da oralidade.
} 
garrafa de SN2; no Corpus do Português aparecem 71 unidades de análise ${ }^{12}$, o que nos garante observar os fatores que contribuem para o cumprimento dos objetivos da pesquisa.

\section{Análise dos dados}

Passaremos agora à análise dos dados coletados no Corpus do Português. Para essa análise, coletamos 103 unidades de análise ${ }^{13}$ de construções binominais do tipo SN1 de SN2 com o objetivo de identificar os fatores formais em análise que permitem que esse grupo de construtos possa ser mapeado ora pela mesoconstrução qualitativa, ora pela mesoconstrução quantitativa. A construção que estamos analisando nessa pesquisa possui a seguinte configuração: (X) SN1 (X) de (X) SN2 (X), em que X faz referência aos elementos circundantes do construto. No entanto, por uma opção metodológica, didática, iremos nos referir a essa construção como SN1 de SN2 ao longo da análise.

Vamos considerar, nessa análise, os seguintes padrões: copo de SN2, garrafa de $\mathrm{SN} 2$, taça de SN2, lata de SN2, vidrinhos de SN2 e pote de SN2. Para tanto, a partir de agora veremos como os construtos binominais com leitura qualitativa e quantitativa comportam-se em relação aos fatores em análise, isto é, tipo de verbo, especificador à esquerda de N1 e modificador depois de N2.

Primeiramente, vejamos as tabelas referentes à frequência da leitura qualitativa e quantitativa em cada um dos padrões de nossa análise.

\footnotetext{
${ }^{12}$ Para a presente pesquisa, coletamos apenas as 30 primeiras ocorrências de cada padrão em análise. Alguns padrões apresentavam muitas ocorrências e outros possuíam poucos exemplares. Como buscávamos inicialmente ter uniformidade na quantidade de dados de cada um dos padrões analisados, realizamos esse recorte.

${ }^{13}$ Nossa primeira intenção, a fim de termos uniformidade na quantidade de dados, era coletar 30 dados de cada um dos padrões que apareceu em nossa análise do livro de crônicas. No entanto, isso não foi possível de ser feito, já que o padrão vidrinhos de SN2 teve apenas uma ocorrência e potes de SN2 e taça de SN2 apresentaram apenas seis dados cada um. Além disso, não foi encontrado o padrão latinha de SN2 no Corpus do Português.
} 
Tabela 1: Frequência das leituras qualitativa e quantitativa no padrão copo de SN2

\begin{tabular}{l|l|l}
\hline LEITURA & NÚMERO & $\%$ \\
\hline QUALITATIVA & 21 & 70 \\
\hline QUANTITATIVA & 9 & 30 \\
\hline TOTAL & 30 & 100 \\
\hline
\end{tabular}

Tabela 2: Frequência das leituras qualitativa e quantitativa no padrão garrafa de SN2

\begin{tabular}{l|l|l}
\hline LEITURA & NÚMERO & $\%$ \\
\hline QUALITATIVA & 22 & 73,3 \\
\hline QUANTITATIVA & 8 & 26,7 \\
\hline TOTAL & 30 & 100 \\
\hline
\end{tabular}

Tabela 3: Frequências das leituras qualitativa e quantitativa no padrão lata de SN2

\begin{tabular}{l|l|l}
\hline LEITURA & NÚMERO & $\%$ \\
\hline QUALITATIVA & 25 & 83,3 \\
\hline QUANTITATIVA & 5 & 16,7 \\
\hline TOTAL & 30 & 100 \\
\hline
\end{tabular}

Tabela 4: Frequência das leituras qualitativa e quantitativa no padrão taça de SN2

\begin{tabular}{l|l|l}
\hline LEITURA & NÚMERO & $\%$ \\
\hline QUALITATIVA & 3 & 50 \\
\hline QUANTITATIVA & 3 & 50 \\
\hline TOTAL & 6 & 100 \\
\hline
\end{tabular}


Tabela 5: Frequência das leituras qualitativa e quantitativa no padrão vidrinhos de SN2

\begin{tabular}{l|l|l}
\hline LEITURA & NÚMERO & $\%$ \\
\hline QUALITATIVA & 1 & 100 \\
\hline TOTAL & 1 & 100 \\
\hline
\end{tabular}

Tabela 6: Frequência das leituras qualitativa e quantitativa no padrão pote de SN2

\begin{tabular}{l|l|l}
\hline LEITURA & NÚMERO & $\%$ \\
\hline QUALITATIVA & 5 & 83,3 \\
\hline QUANTITATIVA & 1 & 16,7 \\
\hline TOTAL & 6 & 100 \\
\hline
\end{tabular}

Através da análise das tabelas, percebemos que a maior quantidade de dados nos padrões observados apresenta leitura qualitativa, com exceção da Tabela 4, em que cada uma das leituras apresentou 50\% das ocorrências. Do total de seis dados de taça de SN2, três apresentaram leitura qualitativa e três apresentaram leitura quantitativa. A grande frequência da leitura qualitativa em relação à quantitativa provavelmente nos indica que a associação do construto à mesoconstrução quantitativa foi incorporada à macroconstrução SN1 de SN2 posteriormente.

Se pensarmos no exemplo xícara de chá, com seu valor original referente à indicação de tipo de xícara, podemos postular que os itens lexicais que instanciam N1 nos construtos que são objeto de estudo da pesquisa, como xícara, quando instanciam uma construção binominal, passam por um processo de extensão claro e regular, isto é, um processo de generalização de contextos, conforme Alonso e Fumaux (2010) e Martelotta (2011) observaram em relação ao uso da construção um bocado de N. Tal processo pode ter ocorrido pela frequência de uso desses itens lexicais. Nessa mudança, os elementos perderam seu valor semântico, passando a estabelecer com SN2 a relação CONTINENTE-CONTEÚDO. No caso do construto xícara de chá, a construção passou a expressar a quantidade de chá que cabe em uma xícara. 


\section{[[xícara ]de chá]}

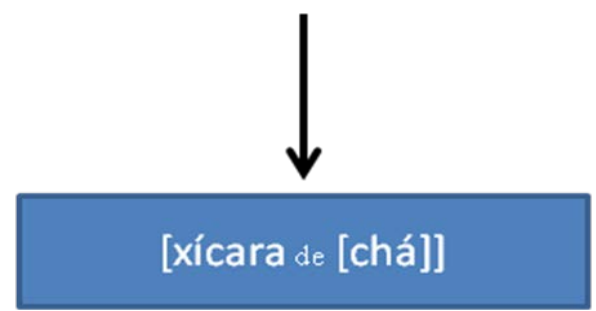

Figura 1: Construto: qualidade para quantidade

Com a observação das tabelas, foi possível constatar que os construtos com leitura qualitativa são mais frequentes no corpus analisado. Isso acarretou uma reorientação do nosso foco em relação aos dados, e passamos, então, a observar os fatores que poderiam favorecer a leitura quantitativa desses construtos, já que ocorreram com menor frequência. No entanto, cabe salientar que também observaremos os fatores recorrentes na leitura qualitativa.

Abaixo seguem as tabelas que dizem respeito ao cruzamento dos fatores (i) tipo semântico do verbo, (ii) elemento à esquerda de N1, e (iii) modificador à esquerda de N2, no padrão copo de SN2. Vale ressaltar que postulamos hipóteses para cada um desses fatores.

Com o primeiro fator analisado, buscamos identificar os tipos semânticos dos verbos relacionados com cada uma das leituras que podem ser feitas para esses construtos, a fim de mapear aqueles verbos que servem como pista para a leitura quantitativa. Para tanto, utilizamos a classificação proposta por Scheibman (2001), que, por sua vez, toma como base as classificações feitas em Halliday (1994) e Dixon (1991), a saber: verbos corpóreos, verbos de atividade verbal, verbos de sentimento, verbos de percepção, verbos de percepção/relacional, verbos materiais, verbos de cognição, verbos de crença, verbos existenciais, verbos relacionais, verbos possessivos, verbos modais e verbos leves.

A partir dessa classificação tipológica dos autores, foi possível postular previamente algumas hipóteses, a saber: 
(i) verbos corpóreos estariam relacionados com a leitura quantitativa, já que tais verbos implicam uma atividade fisiológica ou corpórea, como a ingestão de alimentos/bebidas em geral e, portanto, teriam como foco o conteúdo e não o continente;

(ii) os verbos relacionais e existenciais, como ser e haver, tenderiam a relacionar-se mais efetivamente com a leitura qualitativa, já que eles fornecem atributos para identificação de algo no mundo concreto e fazem referência a objetos no espaço;

(iii) os verbos materiais, pelo seu caráter mais geral de indicar ações cotidianas, podem anteceder tanto construtos de leitura qualitativa, quanto aqueles com leitura quantitativa.

Apesar de nossas hipóteses estarem especificando três classes de verbos, consideramos, em nossa análise, os 13 tipos propostos pelos autores, já que nosso objetivo é identificar os fatores possíveis de orientar a interpretação quantitativa. Nesse caso, nos interessa mapear os tipos de verbos que favorecem essa leitura. Dessa forma, na análise, todos os tipos verbais que aparecem nos dados serão comentados.

Agora passamos para as tabelas com suas respectivas análises.

Tabela 7: Cruzamento do fator tipo de verbo X leitura no padrão copo de SN2

\begin{tabular}{|c|c|c|c|}
\hline & \multicolumn{2}{|c|}{ LEITURA } & TOTAL \\
\hline TIPO DE VERBO & $\begin{array}{c}\text { QUALITATIVA } \\
\text { N\% }\end{array}$ & $\begin{array}{c}\text { QUANTITATIVA } \\
\text { N\% }\end{array}$ & \\
\hline CORPÓREO & $0(0 \%)$ & $4(44,4 \%)$ & $4(13,3 \%)$ \\
\hline PERCEPÇÃO & $2(9,5 \%)$ & $0 \quad(0 \%)$ & $2 \quad(6,7 \%)$ \\
\hline MATERIAL & 17 (81\%) & $5(55,6 \%)$ & $22 \quad(73,3 \%)$ \\
\hline RELACIONAL & 2 (9,5\%) & $0 \quad(0 \%)$ & 2 (6,7\%) \\
\hline Total & $21(100 \%)$ & $9(100 \%)$ & 30 (100\%) \\
\hline
\end{tabular}

Observando o padrão copo de SN2, com ocorrência de verbos corpóreos, constatamos que os quatro verbos corpóreos que aparecem nesse padrão estão relacionados estritamente com a leitura quantitativa. A seguir, apresentamos um exemplo, do Corpus do Português, do padrão apresentado: 
(18) "Ficava me revirando na cama, levantava, bebia um copo de água, voltava." (19Or:Br:Intrv:ISP)

Conforme esperávamos, o verbo corpóreo beber parece favorecer a leitura quantitativa, já que possui como complemento um objeto afetado, consumível. No exemplo acima, um copo de água representa o objeto afetado pelo verbo beber.

Consideramos também como um fator formal, relacionado aos construtos, a natureza do elemento à esquerda do N1. Com esse fator, buscamos identificar a semântica dos elementos que povoam a margem esquerda do N1 em construtos com leitura quantitativa. Postulamos algumas categorias $^{14}$ de elementos que poderiam aparecer na posição anterior à SN1, são eles:

(a) Especificadores: artigos definidos, artigos indefinidos, numerais, pronomes possessivos, pronomes demonstrativos, pronomes indefinidos;

(b) Palavra invariável: preposição;

(c) Ausência de elemento à esquerda de N1.

As hipóteses formuladas para esse fator são:

(i) O numeral deve associar-se unicamente à leitura quantitativa, já que possibilitam a referência a conceitos e objetos como dados passíveis de quantificação exata, caracterizando-se, assim, como quantificadores definidos;

(ii) Os artigos definidos e indefinidos devem estar relacionados com a leitura qualitativa.

Observemos como os dados estão dispostos na tabela abaixo:

\footnotetext{
${ }^{14}$ Alguns autores, como Azeredo (2008) e Mira Mateus (2003), classificam o artigo indefinido como pronomes indefinidos. Também não há consenso em relação aos numerais. Azeredo (2008, p. 173) afirma que "não há nenhuma razão para conferir uma classe à parte a essas palavras [...] os numerais são substantivos ou adjetivos.”. Já Mira Mateus (2003) os classifica como quantificador definido, uma subclasse de pronomes. No entanto, seguimos a tradição gramatical para a análise das classes gramaticais, pois acreditamos que, dessa forma, a análise seria feita com maior precisão, já que os numerais estão diretamente relacionados a uma das leituras dos construtos em foco na pesquisa.
} 
Tabela 8: Cruzamento do fator elemento à esquerda de SN1 X leitura no padrão copo de SN2

\begin{tabular}{|c|c|c|c|}
\hline & \multicolumn{2}{|c|}{ LEITURA } & TOTAL \\
\hline ELEMENTO À ESQUERDA & QUALITATIVA & QUANTITATIVA & \\
\hline DE SN1 & N\% & N\% & N\% \\
\hline ARTIGO DEFINIDO & $8 \quad(42,1 \%)$ & $0(0 \%)$ & $8 \quad(26,7 \%)$ \\
\hline ARTIGO INDEFINIDO & $7 \quad(36,8 \%)$ & $0(0 \%)$ & $7 \quad(23,3 \%)$ \\
\hline NUMERAL & $0 \quad(0 \%)$ & $10(91 \%)$ & $10(33,4 \%)$ \\
\hline PRON. POSSESSIVO & $3(15,8 \%)$ & $0 \quad(0 \%)$ & $3(10 \%)$ \\
\hline ART. DEF. DENTRO DE SP & $1(5,3 \%)$ & $0(0 \%)$ & $1(3,3 \%)$ \\
\hline NUMERAL DENTRO DE SP & $0 \quad(0 \%)$ & $1(9 \%)$ & 1 (3,3\%) \\
\hline Total & $19(100 \%)$ & $11(100 \%)$ & $30(100 \%)$ \\
\hline
\end{tabular}

A partir da observação da disposição dos 30 dados do padrão copo de SN2, na Tabela 8, percebemos que a leitura quantitativa apenas ocorreu com numeral e numeral dentro de SP. Vejamos um exemplo de cada elemento à esquerda de SN1:

(19) “D. Alice recebia-o com um copo de suco de frutas e um carinhoso..." (19:Fic:Br:Holanda:Burro)

(20) “... deve o paciente, em jejum, tomá-las pela manhã, dissolvidas num copo de leite da própria besta...” (19:Fic:Br:Gomes:Rios)

No exemplo (19), o numeral um antecede o construto copo de suco. Além da presença do numeral, o MCI de recepção e o modificador de frutas caracterizando N2 (suco) também orientam a leitura quantitativa. No exemplo seguinte, o numeral um (dentro de um SP) antecede o frame ativado pelo verbo corpóreo tomar.

Ainda nessa tabela referente ao padrão copo de SN2, ressaltamos que o numeral apenas ocorre com a leitura quantitativa, conforme o esperado. Observemos outro exemplo em que se mostra a composição do leite: 
(21) “o leite é uma farinha produzida nos laboratórios, duas colheres de pó e um copo de água- eis o leite.” (19:Fic:Br:Cony:Piano)

Com o próximo fator, pretendemos verificar a presença ou ausência de modificador após N2. Verificaremos, ainda, se modificam apenas N2 ou a construção como um todo, a fim de relacionar com a leitura qualitativa e quantitativa.

Para esse fator, postulamos as seguintes hipóteses:

(i) Os construtos com leitura qualitativa devem apresentar maior frequência de ausência de modificador após SN2. Como, nessa leitura, o foco é o SN1, o modificador deveria aparecer em uma posição entre os nomes, conforme a construção a seguir ilustra: SN1 (X) de SN2;

(ii) Os construtos com leitura quantitativa devem apresentar maior frequência de ausência de modificador após SN2, já que o foco está no SN2 no conteúdo, não havendo necessidade de qualificar tal elemento.

Tabela 9: Cruzamento do fator modificador depois de SN2 X leitura no padrão copo de SN2

\begin{tabular}{c|c|c|c}
\hline \multirow{2}{*}{} & \multicolumn{2}{|c|}{ LEITURA } & TOTAL \\
Modificador depois de SN2 & $\begin{array}{c}\text { QUALITATIVA } \\
\text { N\% }\end{array}$ & $\begin{array}{c}\text { QUANTITATIVA } \\
\text { N\% }\end{array}$ & \\
\hline PRESENÇA & $2(9,5 \%)$ & $5(55,5 \%)$ & $7(23,3 \%)$ \\
\hline AUSÊNCIA & $19(90,5 \%)$ & $4(44,5 \%)$ & $23(76,7 \%)$ \\
\hline \multicolumn{1}{c|}{ Total } & $21(10 \%)$ & $9(100 \%)$ & $30(100 \%)$ \\
\hline
\end{tabular}

A partir da observação da tabela acima com os dados do corpus em análise, percebemos que a ausência de modificador após SN2 é mais frequente do que a presença desse item.

Além disso, podemos notar que de 30 dados, 23 (76,7\%) não apresentam modificador depois de segundo nome. Assim, apenas 7 dados apresentam esse elemento. Seguem dois exemplos: 
(22) "eu outro dia tava tomando um copo de leite daquele leite Longa Vida leite Long...” (19Or:Br:LF:Recf)

(23) “o negro erguia no ar o copo de cerveja dourada.” (19:Fic:Br:Abreu:Onde)

O exemplo (22) apresenta leitura quantitativa; percebemos que o modificador atua apenas sobre o N2. Cabe salientar que, no exemplo (23), o construto copo de cerveja recebe leitura qualitativa. No entanto, o modificador após N2 também possui como escopo o segundo nome, cerveja, o que não era esperado em relação à leitura qualitativa.

Neste momento, após a análise dos dados no padrão copo de SN2, podemos observar em nosso corpus que há propriedades mais frequentes relacionadas com cada uma das leituras. Dessa forma, teríamos um protótipo, um caso central, da leitura quantitativa e outro da leitura qualitativa.

\section{Considerações finais}

Realizados os cruzamentos ${ }^{15}$ das leituras quantitativa e qualitativa com os fatores formais já enunciados nos seis padrões analisados, pudemos chegar a algumas considerações acerca dos construtos binominais em foco neste estudo, em consonância com outras pesquisas que, de certa forma, fazem referência ao que pesquisamos neste trabalho, ou seja, às construções binominais, como Alonso (2010), Traugott (2008) e Alonso e Fumaux (2010, inédito).

No que tange ao tipo de verbo que antecede o construto, ocorreu o que esperávamos, ou seja, houve uma tendência de os verbos materiais ligarem-se aos construtos com leitura quantitativa e qualitativa, já que esses verbos fazem referência a ações concretas e abstratas do nosso dia a dia. Houve também predominância de verbos corpóreos quando a leitura do construto era quantitativa, confirmando nossa hipótese.

No que concerne ao elemento à esquerda de N1, também ocorreu o que esperávamos, pois, o numeral associa-se frequentemente à leitura quantitativa. De

\footnotetext{
15 Conferir em Santos (2014) todas as tabelas referentes aos cruzamentos das leituras quantitativa e qualitativa com os fatores formais, nos seis padrões analisados.
} 
acordo com nossas hipóteses, os artigos indefinidos e definidos restringiram-se a anteceder construtos com leitura qualitativa.

Em relação ao modificador após o N2, postulamos que a ausência desse elemento seria mais frequente tanto na leitura qualitativa, quanto na leitura quantitativa. Isso foi comprovado com a análise dos dados, já que do total de unidades de análise, 86 $(83,4 \%)$ não possuem esse elemento após o N2. Considerando o que analisamos neste trabalho, podemos dizer que a macroconstrução binominal SN1 de SN2 no Português do Brasil está associada a duas mesoconstruções, são elas: qualitativa e quantitativa.

Visto isso, podemos postular o seguinte protótipo do construto com leitura quantitativa:

\section{V material [[num N1] de N2Ø]}

Já para os construtos com leitura qualitativa, chegamos à seguinte configuração prototípica:

\section{V material [art. def. N1 de [N2Ø]]}

Dessa forma, chegamos a uma configuração prototípica dos construtos com leitura qualitativa e daqueles com leitura quantitativa. Esses seriam, então, os exemplares fortes, centrais (BYBEE, 2010) dos construtos que estão na fronteira entre a qualidade e a quantidade. Dessa forma, alguns exemplares podem estar mais perto ou mais distantes desses exemplares. Assim, caso algum construto com leitura quantitativa não apresente um numeral antes da construção, isso não significa que ele não faça parte desse grupo de construtos, mas sim que ele se afasta, de certa forma, do exemplar central de sua categoria.

Esta pesquisa associa-se, como visto ao longo do trabalho, a uma abordagem linguística que considera que as unidades da língua são construções, pares indissociáveis de forma e função. Traugott e Trousdale (2013) elencam princípios comuns às perspectivas construcionais. Entre eles, podemos citar: (i) a unidade básica de gramática é a construção, que é um pareamento convencional de forma e significado; (ii) a estrutura semântica é mapeada diretamente da estrutura sintática, sem derivações; (iii) a linguagem, assim como outros sistemas cognitivos, é uma rede de nós e links, 
ligada por relações de herança entre as construções; (iv) a estrutura da linguagem é moldada pelo uso.

A partir da adoção dessa perspectiva teórica que esta pesquisa se desenvolveu. Consideramos a gramática de uma língua como uma rede de construções interligadas, por exemplo, por relações de polissemia ou pela noção de protótipo, apontada nesta pesquisa na postulação de uma contraparte formal prototípica para os construtos com leitura qualitativa e quantitativa.

Tendo em vista o que analisamos aqui, podemos dizer que avançamos, em relação à análise de um grupo de construtos frequentes no português, ao levantarmos uma contraparte formal para os construtos binominais que flutuam entre a qualidade e a quantidade. Cientes de que a presente pesquisa não encerra a questão do grupo de construtos em foco na pesquisa e de suas manifestações na língua, esperamos ter aberto novas perspectivas e novos olhares acerca do tema em estudo.

ALONSO, Karen Sampaio; SANTOS, Carolina Piechotta Martins. Binominal constructions of NP1 of NP2 type. Revista do Gel, v. 14, n. 1, p. 157-185, 2017.

Abstract: The aim of this work is to investigate binominal constructions (NP1 of NP2) in Brazilian Portuguese, in terms of the different meanings (qualitative and quantitative senses) they could be associated to. For example: xícara de chá [cup of tea] could be interpreted as a type of a cup or the quantity of tea we usually associate to a cup. The research is based on the Usage-based Functional Linguistics (BYBEE, 2010; BARLOW; KEMMER, 2000; TOMASELLO, 2003; TRAUGOTT, 2008). This work describes morphosyntactic, semantic-pragmatic and cognitive properties of the constructions, which favors both qualitative and quantitative perspective regarding the relationship between NP1 of NP2.

Keywords: Usage-based Functional Linguistics. Binominal Constructions. Quantity. Quality.

Submetido em: 10/05/2016.

Aceito em: 31/08/2016. 


\section{Referências}

ADAM, J. M. Les texts: types e prototypes. Paris: Nathan, 1992.

ALMEIDA, C. A. V. et alii. Breve introdução à Linguística Cognitiva. In: ALMEIDA M. L. L.; FERREIRA, R. G.; PINHEIRO, D.; SOUZA, J. de L.; GONÇALVES, C. A. (Org.). Linguística Cognitiva em foco: morfologia e semântica do português. Rio de Janeiro: Publit, 2009.

ALONSO, K. S. B. Construções binominais quantitativas e construção de modificação de grau: uma abordagem baseada no uso. 2010. 152 f. Tese (Doutorado em Linguística) - Faculdade de Letras, Universidade Federal do Rio de Janeiro. Rio de Janeiro, 2010.

ALONSO, K.; FUMAUX, N. Construções binominais qualitativas: uma perspectiva sobre lexicalização. Rio de Janeiro: UFRJ, 2010. (inédito)

AZEREDO, J. C. Gramática Houaiss da Língua Portuguesa. 2. ed. São Paulo: Publifolha, 2008.

BARLOW, M.; KEMMER, S. (Org.). Usage based models of language. Stanford, California: CSLI Publications, 2000.

BYBEE, J. Language, usage, and cognition. Cambridge, UK: CUP, 2010.

CROFT, W. Radical Construction grammar: syntactic theory in typological perspective. Oxford: Oxford University Press, 2001.

DIXON, R. M. W. A new approach to English grammar, on semantic principles. Oxford: Claremdon Press, 1991.

FERRARI, L. Introdução à Linguística Cognitiva. São Paulo: Contexto, 2011.

GOLDBERG, A. E. Constructions: A construction grammar approach to argument structure. Chicago: University of Chicago Press, 1995.

HALLIDAY, M. K. An introduction to Functional Grammar. 2. ed. London: Edward Arnold, 1994.

JOHSON, M. The body in the mind: the bodily basis of meaning, imagination, and reason. Chicago: University of Chicago Press, 1987.

LAKOFF, G. Women, fire and dangerous things: what categories reveal about the mind. Chicago: University Press, 1987.

LAKOFF, G.; JOHNSON, M. Metaphors we live by. Chicago: The University of Chicago Press, 1980. 
MARTELOTTA, M. Mudança linguística. São Paulo: Cortez, 2011.

MATEUS, M. H. M. et alii. Gramática da Língua Portuguesa. 5. ed. Lisboa: Editorial Caminho, 2003. (Colecção Universitária/Série LINGUÍSTICA)

SANTOS, C. P. M. Gramática e cognição: um estudo de construções binominais. 2014. 101 f. Dissertação (Mestrado em Linguística) - Faculdade de Letras, Universidade Federal do Rio de Janeiro. Rio de Janeiro, 2014.

SCHEIBMAN, J. Local paterns of subjectivity in person and verb type in American English conversation. In: BYBEE, J.; HOPPER, P. Frequency and the emergence of linguistic structure. Amsterdam/Philadelphia: John Benjamins Publishing Company, 2001.

TALMY, L. Grammatical construal: the relation of grammar to cognition. In: GEER AERTS, D. (Org.). Cognitive Linguistics: Basic Readings. Berlim/Nova York: Mouton de Gruyter, 2006.

TOMASELLO, M. Origens culturais da aquisição do conhecimento humano. São Paulo: Martins Fontes, 2003.

TRAUGOTT, E. C. Grammaticalization, constructions and the incremental development of language: Suggestions from the development of degree modifiers in English. In:

ECKARDT, R.; JÄGER, G.; VEENSTRA, T. (Eds.). Variation, Selection, Development - Probing the Evolutionary Model of Language Change. Berlin/ $\mathrm{New}$ York: Mouton de Gruyter, 2008. p. 219-250.

TRAUGOTT, E. C.; TROUSDALE, G. G. Constructionalization and Constructional Change. Oxford University Press: Oxford, 2013.

VERISSIMO, L. F. Em algum lugar do paraíso. Rio de Janeiro: Objetiva, 2011.

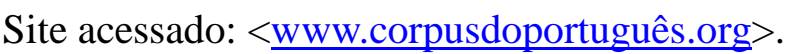

